\title{
Pengaruh Penggunaan Metode Magic Story Terhadap Penguasaan Mufrodat Siswa Kelas VIIB MTs Darul Masholeh Cirebon
}

\author{
Saliqul Abror \\ Institut Agama Islam Negeri (IAIN) Syekh Nurjati Cirebon \\ Email: thewinnerhijab1@gmail.com \\ Wawan Arwani \\ Institut Agama Islam Negeri (IAIN) Syekh Nurjati Cirebon \\ Email: wawanarwani@gmail.com \\ Khasan Aedi \\ Institut Agama Islam Negeri (IAIN) Syekh Nurjati Cirebon \\ Email: khasanaedi@gmail.com
}

\begin{abstract}
Abstrak
Penelitian ini bertujuan untuk megetahui kemampuan siswa dalam menguasai kosakata dalam pembelajaran Bahasa Arab tanpa menggunakan teknik Magic Story, mengetahui kemampuan siswa dalam menguasai kosakata dalam pembelajaran Bahasa Arab dengan menggunakan teknik Magic Story, dan mengetahui pengaruh penggunaan teknik Magic Story terhadap penguasaan kosakata siswa dalam pembelajaran Bahasa Arab pada Kelas VII B di MTs Darul Masholeh. Dalam penelitian ini peneliti menggunakan pendekatan kuantitatif dengan desain eksperimen. Teknik pengumpulan datanya yaitu observasi langsung, tes dan wawancara. Adapun teknik analisis data yang digunakan dalam penelitian ini yaitu uji normalitas, uji homogenitas, dan uji hipotesis. Hasil penelitian pada skripsi ini yaitu: pertama, kemampuan siswa terhadap penguasaan mufrodat sebelum menggunakan Teknik Magic Story tidak ada peningkatan nilai yang tinggi; kedua, kemampuan siswa terhadap penguasaan mufrodat dengan menggunakan Teknik Magic Story terdapat peningkatan nilai yang tinggi; ketiga, pengaruh penggunaan teknik Magic Story terhadap penguasaan mufrodat siswa Berdasarkan hasil uji regresi di atas nilai signifikan. Artinya, ada Pengaruh penggunaan teknik magic story terhadap penguasaan mufrodat siswa.
\end{abstract}

Kata Kunci : Teknik Magic Story, Kosakata, Pembelajaran Bahasa Arab

Abstract

This study aims to determine the ability of students to master vocabulary in learning Arabic without using the Magic Story technique, determine the ability of students to master vocabulary in learning Arabic by using the Magic Story technique, and determine the effect of using the Magic Story technique on students' vocabulary mastery in language learning Arabic in Class VII B at MTs 
Darul Masholeh. In this study, researchers used a quantitative approach to the experimental design. Data collection techniques are direct observation, tests and interviews. The data analysis techniques used in this study are normality test, homogeneity test, and hypothesis testing. The results of the study in this thesis are: first, the ability of students to master the mastery of mufrodat before using the Magic Story Technique there is no increase in high scores; second, the ability of students towards mastery of mufrodat by using the Magic Story Technique there is a high increase in grades; third, the effect of the use of the Magic Story technique on students' mastery of mufrodat Based on the results of the regression test above a significant value. Thus, there is an influence of the use of magic story techniques on mastery of students.

Keywords: Magic Story Techniques, Vocabulary, Arabic Learning

$$
\text { ملخص }
$$

أهداف البحث في هذه الرسالة هي: الأول، لمعرفة قدرة الطلاب على استيعاب مفردات

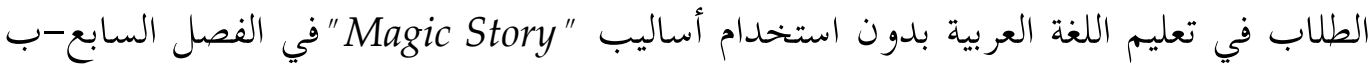
بمدرسة دار المصالح المتوسطة الإسلامية شربون؛ والثانى، لمعرفة قدرة الطلاب على استيعاب مفردات الطلاب في تعليم اللغة العربية باستخدام أساليب "Magic Story" في الفصل السابعب بمدرسة دار المصالح المتوسطة الإسلامية شربون؛ والثالث، لمعرفة تأثير استخدام أساليب "Magic Story"

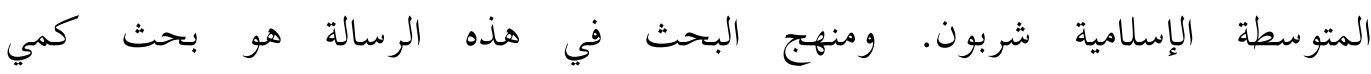
بإجرءاتالبحثالتجريبي. وأما طريقةجمع البيانات فيها الملاحظة المباشرة والاختبار والمقابلة الشخصية. وطريقة تحليل البيانات التي استخدمها الباحث في هیذذا البحث بحساب تقرير الفرقة واختبار العادية واختبار المتجانس واختبار الفرضية. فنتيجة البحث هي قدرة في الطلاب ف "Magic Story" لفى الفصل السابع-ب على استيعاب المفردات العربية قبل تطبيق أساليب ترتقى نتيجة كثيرة، وقدرة الطلاب فى الفصل السابع-ب على استيعاب المفردات العربية بتطبيق أساليب "Magic Story "فى العملية التعليمية لمادة اللغة العربية بمدرسة دار المصالح

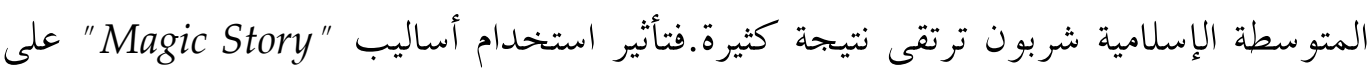
استيعاب المفردات العربية بمدرسة دار المصالح المتوسطة الإسلامية شربون، بناء على نتائج Magic " اختبار الانحدار السابقة قيمة كبيرة، فهذا دليل على أن هناك تأثير استخدام أساليب لعبل "Story 


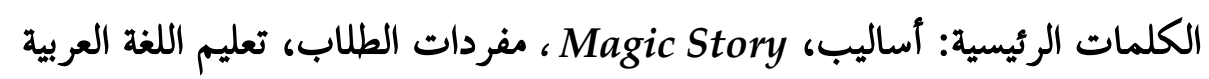

\section{Pendahuluan}

Bahasa adalah dasar dari kehidupan di masyarakat, karena bahasa merupakan sarana untuk saling memahami dan berkomunikasi dalam berbagai bidang. Kondisi yang ideal dalam meningkatkan keterampilan bahasa adalah kita tidak memberikan dua keterampilan yang berbeda pada saat yang sama kepada siswa, seperti melatihnya untuk membentuk kalimat-kalimat baru yang sebelumnya tidak diajarkan/diberikan kepada siswa akan menambah dua kesulitan kepadanya: satu adalah kebutuhan untuk memahami kata-kata baru dan yang lainnya adalah menyusun kalimat-kalimat baru. Terlihat jelas dalam beberapa buku pengajaran bahasa Arab bahwa latihan mereka mencakup kosakata dan struktur yang tidak disebutkan dalam pelajaran sebelumnya, yang membingungkan siswa dan kadang-kadang membuatnya tidak dapat menyelesaikan latihan ini, dan kemudian tujuannya belum tercapai. ${ }^{1}$

Kosakata adalah salah satu komponen yang membangun suatu bahasa, seperti sistem fonemik, struktur kata, dan sistem sintaksis, maka perbedaan bunyi mengarah pada perbedaan makna. ${ }^{2}$

Berdasarkan penjelasan di atas, peneliti menyimpulkan bahwa pemahaman kosakata sangat penting karena kosakata adalah salah satu kemampuan yang harus dikuasai secara mutlak oleh orang yang belajar bahasa Arab. Ahmad Fuadi Effendy juga mengatakan dalam bukunya bahwa kosakata adalah salah satu elemen dari bahasa yang harus dikuasai oleh pelajar bahasa asing agar dapat memperoleh keterampilan komunikasi dengan bahasa Arab. Tidak mungkin untuk berbicara bahasa Arab tanpa kosakata. ${ }^{3}$

Tujuan dari pembelajaran kosakata bukan hanya menguasai pengucapan bunyi-bunyiannya, atau untuk memahami maknanya secara mandiri, atau untuk mengetahui metode yang berasal darinya, atau hanya untuk menggambarkannya dalam struktur linguistik yang benar. Kriteria kemahiran dalam pembelajaran kosakata adalah bahwa siswa dapat melakukan semua ini,

1 Abdurrahman bin Ibrahim Al-Fauzan, Duruus ad-Dauraat at-Tadriis li Mu'allimii al-Lughah al-'arabiyyah lighairi an-Naathiqiina bihaa (al-Jaanib an-Nazharii). (Muassasah al-Waqfi al-Islaamii, Masyruu' al-'Arabiyyah lil jamii', 1425). Hal. 31.

2 Mahmud Ismail Shiinii, dkk, Mursyid al-Mu'allim fii Tadriis al-Lughah al'Arabiyyah lighairi an-Naathiqiina bihaa. (Maktab at-Tarbiyyah al-'Arabiyyah, 1995). Hal. 85.

${ }^{3}$ Ahmad Fuad Effendy, Metodologi Pengajaran Bahasa Arab. (Malang: Misykat, 2005). Hal. 96. 
di samping itu juga menggunakan kosakata yang tepat dalam konteks yang sesuai. ${ }^{4}$

Namun pada kenyataannya banyak siswa yang tidak dapat menggunakan kata atau kosakata dalam konteks yang sesuai, bahkan kebanyakan dari mereka tidak hafal arti dari kosakata yang mereka temukan saat belajar bahasa Arab di sekolah. Mereka merasa sulit menghafal kosakata. Pernyataan ini didasarkan pada wawancara terbatas dengan guru di MTs Darul Masholeh pada 5 November 2018. Guru mengatakan bahwa pembelajaran di MTs Darul Masholeh, tidak berhasil dalam hal bahasa Arab khususnya dalam memahami kosakata. Beberapa faktor yang membuat siswa sulit menghafal kosakata, termasuk ketika peneliti memperhatikan pengajaran bahasa Arab di MTs Darul Masholeh, bahwa guru menggunakan metode dan teknik yang tidak tepat dalam menyajikan kosa kata baru kepada siswa. Guru hanya menggunakan metode ceramah. Selain itu, siswa merasa bahwa bahasa Arab sulit, dan siswa kurang memiliki keinginan untuk belajar bahasa Arab, terutama dalam menghafal kosa kata. Guru berfokus pada menghafal kosakata yang tidak dipraktikkannya dalam kalimat, dan guru cenderung kurang memahami teknik yang digunakannya.

Magic Story adalah sebuah teknik memori paling dasar dari semua teknik memori. ${ }^{5}$ Namun meskipun teknik paling dasar, teknik ini dapat digunakan untuk mengingat informasi-informasi yang sederhana. Ini berarti bahwa teknik Magic Story memungkinkan pengguna untuk menghafal kosa kata.

Berdasarkan fenomena ini, peneliti ingin meneliti dan menganalisis masalah-masalah ini dengan judul "Pengaruh Penggunaan Teknik"Magic Story" terhadap Penguasaan Kosakata Bahasa Arab Siswa (Studi Eksperimen pada Kelas VII B di MTs Darul Masholeh Cirebon.

Dalam penelitian ini masalah yang akan diangkat diantaranya:Sejauh mana penguasaan kosakata siswa dalam belajar bahasa Arab tanpa menggunakan metode "Magic Story",sejauh mana penguasaan kosakata siswa belajar bahasa Arab dengan menggunakan metode "Magic Story", dan sejauh mana pengaruh penggunaan metode "Magic Story" terhadap penguasaan kosakata siswa di Kelas VII B MTs Darul Masholeh Cirebon?

\section{Metode Penelitian}

Metode penelitian yang digunakan dalam penelitian ini yaitu metode eksperimen dengan pendekatan kuantitatif untuk mengetahui pengaruh

${ }^{4}$ Abdurrahman bin Ibrahim al-Fauzan, Duruus ad-Dauraat at-Tadriis li Mu'allimii al-Lughah al-'arabiyyah lighairi an-Naathiqiina bihaa (al-Jaanib an-Nazharii). (Muassasah alWaqfi al-Islaamii, Masyruu' al-'Arabiyyah lil jamii', 1425). Hal. 45.

${ }^{5}$ Erwin Kurnia Wijaya, 3M Magic Memory for Muslim. (Surabaya: Genta Group Production, 2016). Hal. 53. 
penggunaan metode Magic Story terhadap penguasaan kosakata bahasa Arab siswa kelas 7 di MTs Darul Masholeh Cirebon.

Desain yang digunakan dalam penelitian ini yaitu pre experimental dengan mengguanakan desain one group pretest-posttest. Desain ini terdiri dari:

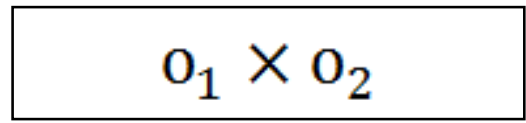

O1 = Pretest

$\mathrm{X}=$ Treatment

O2 =Posttest

Berdasarkan sumbernya, data yang digunakan oleh peneliti untuk memeroleh informasi dalam penelitian ini yaitu sumber data primer dan sumber data sekunder. Sumber data primer dalam penelitain ini yaitu siswa kelas VII B di MTs Darul Masholeh Cirebon dan sumber data sekundernya yaitu buku-buku yang berhubungan dengan penelitian ini.

Populasi dalam penelitian ini yaitu semua siswa kelas VII di MTs Darul Masholeh Cirebon yang terdiri dari 53 siswa. Adapun sampelnya yaitu semua siswa kelas VII-B di MTs Darul Masholeh Cirebon yang berjumlah 27 siswa dengan teknik pengambilan sampel "Cluster Sampling".

Teknik pengumpulan data dalam penelitian ini yaitu observasi, wawancara, dan tes. Observasi yang peneliti gunakan adalah observasi partisipan. Dalam observasi ini peneliti berpartisipasi dalam aktivitas manusia sehari-hari yang digunakan sebagai sumber data (Sugiyono, 2016: 235). Observasi ini digunakan untuk memperoleh informasi selama proses KBM di kelas. Selanjutnya wawancara yang dilakukan peneliti adalah wawancara dengan guru bahasa Arab dan siswa.Adapun tes yang digunakan dalam penelitian ini yaitu pretest dan posttest.

\section{Pengertian Metode Magic Story}

Magic story adalah sebuah teknik memori paling dasar dari semua teknik memori. Teknik ini harus dikuasai dulu sebelum mempelajari metode memori lainnya. Jika teknik ini dikuasai maka teknik-teknik berikutnya akan mudah sekali dipelajari. ${ }^{6}$ Magic story adalah sebuah metode memori paling dasar dari semua teknik memori. Meskipun metode dasar, namun metode ini sudah bisa diaplikasikan untuk mengingat informasi-informasi yang sederhana. Misalnya seperti daftar belanjaan, daftar kata benda, dan daftar kata sifat. Bagaimana

${ }^{6}$ Erwin Kurnia Wijaya, 3M Magic Memory for Muslim. (Surabaya: Genta Group Production, 2016). Hal. 53-54. 
cara melakukan atau membuatnya? Mari ikuti langkah-langkahnya sebagai berikut:

a. Susun cerita imajinasi dari informasi yang akan dihafal, upayakan ceritanya yang lucu dan bahkan tidak masuk akal. Contohnya Lemari Es menonton Televisi, Marmer menelepon Batman, dan sebagainya. Apabila ceritanya semakin kocak maka akan semakin menempel di otak kita.

b. Susun cerita yang Anda buat, lakukanlah secara estafet, yaitu benda pertama melakukan aksi ke benda kedua, benda kedua ke benda ketiga, dan seterusnya.

Contohnya seperti cerita di bawah ini:

"Ada sebuah Tas sedang berjalan membuka sebuah Lemari Es. Lemari Esnya ternyata sedang duduk menonton Televisi. Lalu Televisi ini membacakan Buku Cerita, buku ceritanya berkisah tentang sebuah Tembok yang sangat rapuh, Tembok inipun akhirnya berjalan dengan lunglai membeli Marmer supaya kuat. Marmer ini ternyata menelepon Batman supaya mendapat kekuatan lebih, maka Batman pun kemudian membakar Kertas. Meskipun terbakar, kertasnya lalu berlarian dan bersembunyi ke dalam Magic Jar. Akhirnya Magic Jar itu membuka Kran Air supaya semuanya menjadi dingin kembali dan tidak terbakar."

Apabila digambarkan akan seperti ini:

Tas - Lemari Es - Televisi - Buku Cerita - Tembok - Marmer - Batman Kertas - Magic Jar - Kran Air.

Langkah ini dilakukan agar kita dapat mengurutkan benda dengan benar dan tidak tertukar. Hindari membuat cerita benda pertama ke benda kedua, benda pertama ke benda ketiga, benda pertama ke benda berikutnya lagi. Misalnya, Tas membuka Lemari Es, lalu tasnya menonton televisi, kemudian tasnya membaca buku cerita, dan seterusnya. Contoh seperti ini akan membingungkan saat harus mengurutkan bendanya.

a. Tambahkan bunyi, warna, bau maupun dengan memperbesar atau memperkecil obyek bendanya, jika diperlukan sehingga membuat cerita yang hidup dan aktif.

b. Terakhir dan yang paling penting, bayangkan oleh Anda cerita imajinasi tersebut, seolah-olah menjadi sebuah film yang diputar dalam pikiran kita saat menghafalkan sesuatu.

"Ada sebuah Tas sedang berjalan membuka sebuah Lemari Es. Lemari Esnya ternyata sedang duduk menonton Televisi. Lalu Televisi ini membacakan Buku Cerita, buku ceritanya berkisah tentang sebuah Tembok yang sangat rapuh, Tembok inipun akhirnya berjalan dengan lunglai membeli Marmer supaya kuat. Marmer ini ternyata menelepon Batman supaya mendapat kekuatan lebih, maka Batman pun kemudian membakar Kertas. 
Meskipun terbakar, kertasnya lalu berlarian dan bersembunyi ke dalam Magic Jar. Akhirnya Magic Jar itu membuka Kran Air supaya semuanya menjadi dingin kembali dan tidak terbakar."

Apabila digambarkan akan seperti ini:

Tas - Lemari Es - Televisi - Buku Cerita - Tembok - Marmer - Batman Kertas - Magic Jar - Kran Air.

\section{Pengertian Mufrodat}

Kosakata adalah elemen bahasa yang paling penting. Beberapa ahli bahasa cenderung menganggapnya sebagai elemen bahasa yang paling penting. Yang dimaksud dengan ungkapan ini bahwa kosakata adalah kondisi kunci yang mengarah pada pemahaman makna kalimat dalam posisi komunikasi atau dalam pemahaman teks dan bacaan. ${ }^{7}$

Kosakata adalah alat untuk membawa makna dan di lain waktu sebagai sarana berpikir. Karena pembicara dapat berpikir dan kemudian mengungkapkan apa yang ada dalam pikirannya dan berpikir dalam kata-kata apa yang diinginkannya. ${ }^{8}$

Menurut Al-Khauli dan Mahmud Ali dalam yang dikutip oleh Syaiful dalam bukunya, kosakata merupakan kumpulan kata-kata tertentu yang akan membentuk bahasa. Kata adalah bagian terkecil dari bahasa yang sifatnya bebas. Pengertian ini membedakan antara kata dengan morfem. Morfem adalah satuan bahasa terkecil yang tidak bisa dibagi atas bagian bermakna yang lebih kecil yang maknanya relatif stabil. Maka kata terdiri dari morfem-morfem, misalnya kata mu"allim (معلم) dalam bahasa Arab terdiri dari satu morfem. Sedangkan kata almuallim (المعلم) mempunyai dua morfem yaitu المعلم Adan kata yang terdiri dari tiga morfem adalah kata yang terbentuk dari morfemmorfem dimana masing-masing morfem memiliki arti khusus. Misalnya kata al-mu'allimûn (المعلمون) yang terdiri dari tiga morfem yaitu, معلم) الdaniو. ${ }^{9}$

\section{Macam-Macam Mufrodat}

7 Kamal Ibrahim Badawi dan Abdullah Hatim, Thariqah Tadriis al-Lughah al'Arabiyyah. (Kairo: al-Ma'ariff, 1995). Hal. 10.

8 Mahmud Kamil an-Naqah, Ta'liim al-Lughah al-'Arabiyyah bi Lughaah Ukhra: Ususuhu-Madaakhiluhu-Thuruq Tadriisihi (Makkah al-Mukarramah: Jaami'ah Ummul Qura, 1985). Hal. 161.

9 Syaiful Mustofa, Strategi Pembelajaran Bahasa Arab Inovativ. (Malang: UIN Press, 2011). Hal. 62. 
Menurut Rusydy Ahmad Tha'imah kosakata dibagi menjadi empat bagian, yang dibagi sesuai dengan keterampilan bahasa, sesuai dengan makna dan menurut spesialisasi dan sesuai dengan penggunaannya. Berikut ini penjelasannya: ${ }^{10}$

Pembagian kosakata dalam konteks kemahiran kebahasaan:

a. Kosakata untuk memahami (understanding vocabulary) baik bahasa lisan ( الاستماع) maupun teks ( القراءة).

b. Kosakata untuk berbicara (speaking vocabulary). Dalam pembicaraan perlu penggunaan kosakata yang tepat, baik pembicaraan informal (عادية) maupun formal (موقة)( موقية).

c. Kosakata untuk menulis (writing vocabulary). Penulisan pun membutuhkan pemilihan kosakata yang baik dan tepat agar tidak disalahartikan oleh pembacanya.

d. Kosakata potensial. Kosakata jenis ini terdiri dari kosakata context yang dapat diinterpretasikan sesuai dengan konteks pembahasan, dan kosakata analysis yakni kosakata yang dapat dianalisa berdasarkan karakteristik derivasi kata unuk selanjutnya dipersempit atau diperluas maknanya.

Pembagian kosakata menurut maknanya:

a. Kata-kata inti (content vocabulary). Kosakata ini adalah kosakata dasar yang membentuk sebuah tulisan menjadi valid, misalnya kata benda, kata kerja, dll.

b. Kata-kata fungsi (function words). Kata-kata ini yang mengikat dan menyatukan kosakata dan kalimat sehingga menbentuk paparan yang baik dalam sebuh tulisan. Contohnya hurûf jâr, adawât al-istifhâm, dan seterusnya.

c. Kata-kata gabungan (cluster words). Kosakata ini adalah kosakata yang tidak dapat berdiri sendiri, tetapi selalu dipadukan dengan kata-kata lain sehingga membentuk arti yang berbeda-beda. Misalnya kata رغبdapat berarti menyukai bila kata tersebut dipadukan dengan رغب في رغي Sedangkan bila diikuti

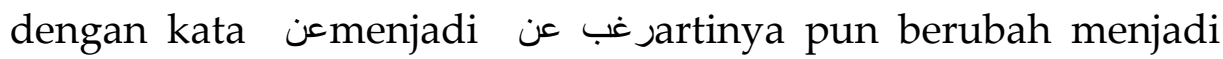
benci atau tidak suka.

Pembagian kosakata menurut karakteristik kata (takhassus):

10 Rusydi Ahmad Thuaimah, al-Marja' fii Ta'liim al-Lughah al-'Arabiyyah lii anNaathiqiina bi Lughaatin Ukhra. (Makkah: Jaami'ah Ummul Qura, 1986). Hal. 616-618. 
a. Kata-kata tugas (service words) yaitu kata-kata yang digunakan untuk menunjukan tugas, baik dalam lapangan kehidupan secara informal maupun formal dan sifatnya resmi.

b. Kata-kata inti khusus (special content words). Kosa kata ini adalah kumpulan kata yang dapat mengalihkan arti kepada yang spesifik dan digunakan di berbagai bidang ulasan tertentu, yang biasa juga disebut local words atau utility words.

Pembagian kosakata menurut penggunaannya:

a. Kosakata aktif (active words), yakni kosakata yang umumnya banyak digunakan dalam berbagai wacana.

b. Kosakata pasif (passive words), yaitu kosakata yang hanya menjadi perbendaharaan kata seseorang namun jarang ia gunakan.

\section{Dasar-Dasar Pemilihan Kosakata}

Berapa banyak bahasa yang Anda berikan kepada diri Anda sendiri, dan Anda harus memilih dari mereka dan apa yang mendasari pemilihan kosakata dalam program untuk mengajar bahasa Arab kepada penutur dalam bahasa lain? Berikut ini terdapat beberapa dasar pemilihan kosakata:

a. Frequency, yaitu frekuensi penggunaan kata-kata yang tinggi dan sering itulah yang harus menjadi pilihan.

b. Range, yaitu mengutamakan kata-kata yang banyak digunakan baik di negara Arab maupun di negara-negara non Arab atau di suatu negara tertentu yang mana kata-kata itu lebih sering digunakan.

c. Availability, mengutamakan kata-kata atau kosakata yang mudah dipelajari dan digunakan dalam berbagai media atau wacana.

d. Familiarity, yakni mendahulukan kata-kata yang sudah dikenal dan cukup familiar didengar, seperti penggunaan kata digunakan dari pada kata ذّ

e. Coverage, yakni kemampuan daya cakup suatu kata untuk memiliki beberapa arti, sehingga menjadi luas cakupannya. Misalnya kata يبت lebih luas daya cakupannya dari pada kata منزل.

f. Significance, yakni mengutamakan kata-kata yang memiliki arti yang signifikan untuk menghindari kata-kata umum yang banyak ditinggalkan atau kurang lagi digunakan.

g. Arabism, yakni mengutamakan kata-kata Arab dari kata-kata serapan yang diarabisasi dari bahasa lain. Misalnya kata التنفاز ,الهذياع,الهاتف 
secara berurutan ini harus diutamakan pemilihannya dari pada kata

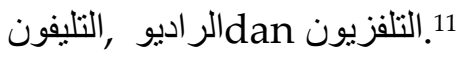

\section{Pembelajaran Mufrodat}

Yang dimaksud pembelajaran mufrodat (kosakata) adalah interaksi antara guru dan murid yang mempelajari makna kata bahasa Arab dengan tujuan agar dapat menguasai mufrodat tidak hanya sekedar hafal kosakata tetapi mampu menggunakannya dalam berkomunikasi, menulis, dan menerjemahkan. ${ }^{12}$

Tujuan umum pembelajaran kosakata (mufradât) bahasa Arab adalah sebagai berikut:

a. Memperkenalkan kosakata baru kepada siswa, baik melalui bacaan maupun fahm al-masmu'.

b. Melatih siswa untuk dapat melafalkan kosakata itu dengan baik dan benar, karena pelafalan yang baik dan benar mengantarkan kepada kemahiran berbicara dan membaca secara baik dan benar.

c. Memahami makna kosakata, baik secara denotasi atau leksikal maupun ketika digunakan dalam konteks kalimat tertentu.

d. Mampu mengapresiasi dan memfungsikan mufradât itu dalam berekspresi lisan maupun tulisan sesuai dengan konteksnya. ${ }^{13}$

Dalam pembelajaran kosakata ada beberapa hal yang harus diperhatikan, sebagai berikut: ${ }^{14}$

a. Pembelajaran kosakata (al-mufradât) tidak berdiri sendiri. Kosakata (almufradât) hendaknya tidak diajarkan sebagai mata pelajaran yang berdiri sendiri melainkan sangat terkait dengan pembelajaran muthâla'ah, istimấ, insyâ', dan muhâdatsah.

b. Pembatasan makna. Dalam pembelajaran kosakata hendaknya makna harus dibatasi sesuai dengan konteks kalimat saja, mengingat satu kata dapat memiliki beberapa makna.

c. Kosakata dalam konteks. Beberapa kosakata dalam bahasa asing (Arab) tidak bisa dipahami tanpa pengetahuan tentang cara

${ }^{11}$ Rusydi Ahmad Thuaimah, Ta'liim al-'Arabiyyah lighairi an-Naathiqiina bihaa. (ar-Ribaath: Mausyuuraat al-Munazzhamah al-Islaamiyyah wa al-`Uluum wa atsTsaqaafah, 1989). Hal. 195-196.

12 Bisri Musthofa, Hamid M. Abdul, Metode E Stategi Pembelajaran Bahasa Arab. (Malang: UIN Maulana Malik Ibrahim Press, 2012). Hal. 68.

13 Syaiful Mustofa, Strategi Pembelajaran Bahasa Arab Inovativ. (Malang: UIN Press, 2011). Hal. 63.

14 Ahmad Fuad Effendy, Metodologi Pengajaran Bahasa Arab. (Malang: Misykat, 2005). Hal. 97-98. 
pemakaiannya dalam kalimat. Kosakata seperti ini hendaknya diajarkan dalam konteks agar tidak mengaburkan pemahaman siswa.

d. Terjemah dalam pengajaran kosakata. Pembelajaran kosakata dengan cara menerjemahkan kata ke dalam bahasa ibu adalah cara yang paling mudah, namun mengandung beberapa kelemahan. Kelemahan tersebut antara lain dapat mengurangi spontanitas siswa ketika menggunakannya dalam ungkapan saat berhadapan dengan benda atau objek kata, lemah daya lekatnya dalam ingatan siswa, dan juga tidak semua kosakata bahasa asing ada padanannya yang tepat dalam bahasa ibu.

e. Tingkat kesukaran. Bila ditinjau dari tingkat kesukarannya, kosakata bahasa Arab bagi pelajara di Indonesia dapat dibedakan menjadi tiga, antara lain:

a) Kata-kata yang mudah, karena ada persamaannya dengan katakata dalam bahasa Indonesia, seperti : رحمة ، كرسي ، كتاب ، علماء.

b) Kata-kata yang sedang dan tidak sukar meskipun tidak ada persamaannya dalam bahasa Indonesia, seperti : مدينـة ، سوق ، ذهب.

c) Kata-kata yang sukar, baik karena bentuknya maupun pengucapannya, misalnya : انزلق ، تدهور ، استولى.

\section{Tes Kosakata}

Abdul-Rahman ibn Ibrahim al-Fawzan mengatakan bahwa ujian penting untuk mengevaluasi pendidikan, terutama untuk mengetahui sejauh mana kosakata dipahami oleh siswa, diantaranya tes sinonim dan tes antonim. ${ }^{15}$

Menurut M. Ali Al-Khuli (1989: 159-160) dimungkinkan untuk menguji kosa kata dalam beberapa caradiantaranya multi-test, sinonim, penjelasan, antonim, derivasi, menjodohkan, mengisi yang kosong.

Berdasarkan uraian di atas, peneliti merangkum bahwa ada beberapa tipe yang dapat digunakan dalam tes kosakata termasuk: tes sinonim, tes antonim, multi-tes, penjelasan, derivasi, menjodohkan, mengisi yang kosong, menganalisis kesalahan, menentukan bentuk mufrod, menentukan bentuk jamak, membuat kalimat, dan penguasaan makna kata.

15 Abdurrahman bin Ibrahim al-Fauzan, Duruus ad-Dauraat at-Tadriis $l i$ Mu'allimii al-Lughah al-'arabiyyah lighairi an-Naathiqiina bihaa (al-Jaanib anNazharii). (Muassasah al-Waqfi al-Islaamii, Masyruu' al-'Arabiyyah lil jamii', 1425). Hal. 55. 


\section{Indikator Penguasaan Kosakata}

Pembelajaran kosakata bukan hanya sekedar mengajarkan kosakata kemudian menyuruh siswa untuk menghafalkannya, akan tetapi lebih dari itu siswa dianggap mampu menguasai mufradât jika sudah mencapai indikator-indikator penguasaan mufradât antaralain: (1) siswa mampu menerjemahkan bentuk-bentuk mufradât dengan baik; (2) siswa mampu mengucapkan dan menulis kembali mufradât dengan baik dan benar; (3) siswa mampu menggunakan mufradât dalam jumlah (kalimah) dengan benar, baik dalam bentuk ucapan maupun tulisan. ${ }^{16}$

Sejalan dengan pendapat di atas Ali Al-Khuli mengemukakan bahwa indikator penguasaan mufrodat sebagai berikut: (1) Siswa mampu untuk mengucapkan kata dengan benar; (2) siswa mampu untuk menerjemahkan kosa kata dengan baik; (3) siswa mampu untuk menulis kata tanpa salah eja; (4) siswa mampu untuk membaca kata dengan benar. ${ }^{17}$

\section{Hasil Penelitian}

\section{Sebelum Penggunaan Metode Magic Story}

Statistics

\begin{tabular}{|c|c|c|}
\hline \multicolumn{3}{|c|}{ Pretest } \\
\hline & Valid & 27 \\
\hline & Missing & 0 \\
\hline \multicolumn{2}{|c|}{ Mean } & 52.7407 \\
\hline \multicolumn{2}{|c|}{ Median } & 53.0000 \\
\hline \multicolumn{2}{|c|}{ Mode } & $53.00^{\mathrm{a}}$ \\
\hline \multicolumn{2}{|c|}{ Std. Deviation } & 12.26500 \\
\hline \multicolumn{2}{|c|}{ Variance } & 150.430 \\
\hline \multicolumn{2}{|c|}{ Minimum } & 33.00 \\
\hline \multicolumn{2}{|c|}{ Maximum } & 73.00 \\
\hline \multicolumn{2}{|c|}{ Sum } & 1424.00 \\
\hline
\end{tabular}

16 Syaiful Mustofa, Strategi Pembelajaran Bahasa Arab Inovativ. (Malang: UIN Press, 2011). Hal. 60.

${ }^{17 M u h a m m a d}$ 'Ali al-Khuli, Asaaliib Tadriis al-Lughah al-'Arabiyyah. (Riyadh: tidak diterbitkan, 1986). Hal. 103. 
Berdasakan tabel statistik di atas jumlah responden sebanyak 27siswa. Missing 0 menunjukkan bahwa data yang hilang adalah nol, dengan demikian tidak ada data yang belum diproses.

Mean atau rata-rata pretes sebesar 52,74, median sebesar 53, Modus diperoleh 53, sementara nilai minimal dan maksimal masing-masing sebesar 33 dan 73 dengan jumlah total pretes sebesar 1424 .

\section{Setelah Penggunaan Metode Magic Story}

\section{Statistics}

\begin{tabular}{|c|c|c|}
\hline \multicolumn{3}{|c|}{ Postest } \\
\hline \multirow{2}{*}{$\mathrm{N}$} & Valid & 27 \\
\hline & Missing & 0 \\
\hline \multicolumn{2}{|c|}{ Mean } & 80.3704 \\
\hline \multicolumn{2}{|c|}{ Median } & 80.0000 \\
\hline \multicolumn{2}{|c|}{ Mode } & 73.00 \\
\hline \multicolumn{2}{|c|}{ Std. Deviation } & 7.15299 \\
\hline \multicolumn{2}{|c|}{ Variance } & 51.165 \\
\hline \multicolumn{2}{|c|}{ Minimum } & 73.00 \\
\hline \multicolumn{2}{|c|}{ Maximum } & 93.00 \\
\hline \multicolumn{2}{|c|}{ Sum } & 2170.00 \\
\hline
\end{tabular}

Berdasakan table statistics di atas jumlah responden sebanyak 27 siswa. Missing 0 menunjukkan bahwa data yang hilang adalah nol, dengan demikian tidak ada data yang belum diproses.

Mean atau rata-rata postes sebesar 80,37 , median sebesar 80 , mode didapat 73 sementara nilai minimal dan maksimal masing-masing sebesar 73 dan 93 dengan jumlah total postes sebesar 2170.

Pengaruh Penggunaan Metode Magic Story terhadap Peningkatan Mufrodat Siswa

1. Uji Normalitas

Uji normalitas dilakukan untuk mengetahui apakah data berdistribusi normal atau tidak. Pada pembahasan ini, uji normalitas dilakukan dengan menggunakan uji KolmogorovSmirnova.

Dasar pengambilan keputusan dalam pengujian normalitas data dengan menggunakan uji Kolmogorov-Smirnovayaitu :

a. Nilai sig. atau signifikansi atau nilai probabilitas $>0,05$, maka data berdistribusi normal. 
b. Nilai sig. atau signifikansi atau nilai probabilitas $<0,05$, maka data berdistribusi data tidak normal.

One-Sample Kolmogorov-Smirnov Test

\begin{tabular}{|c|c|c|c|}
\hline & Pretest & Postest \\
\hline \multirow[t]{2}{*}{$\mathrm{N}$} & & 27 & 27 \\
\hline & Mean & 52.7407 & 80.3704 \\
\hline Normal Parameters ${ }^{\mathrm{a}, \mathrm{b}}$ & $\begin{array}{l}\text { Std. } \\
\text { Deviation }\end{array}$ & 12.26500 & 7.15299 \\
\hline \multirow{3}{*}{$\begin{array}{l}\text { Most Extreme } \\
\text { Differences }\end{array}$} & Absolute & .130 & .256 \\
\hline & Positive & .116 & .256 \\
\hline & Negative & -.130 & -.192 \\
\hline \multicolumn{2}{|l|}{ Kolmogorov-Smirnov Z } & .678 & 1.330 \\
\hline \multicolumn{2}{|l|}{ Asymp. Sig. (2-tailed) } & .748 & .058 \\
\hline
\end{tabular}

a. Test distribution is Normal.

b. Calculated from data.

Hasil uji normalitas pada tabel di atas data pretest menunjukkan nilai signifikan sebesar 0,748. Karena tersebut nilai signifikan berada di atas 0,05. Maka data pretest siswa berdistribusi normal.

Hasil uji normalitas pada data postest menunjukkan nilai signifikan pada uji kolmogorov sebesar 0,058. Karena tersebut nilai signifikan berada di atas 0,05 . Maka data postest berdistribusi normal

2. Uji Homogenitas

Uji homogenitas dilakukan untuk mengetahui kesamaan antara keadaan atau populasi. Untuk menguji Homogenitas kedua sampel dilakukan dengan menganalisa Varians masing-masing dari data. Berikut adalah hasil dari uji homogenitas yang dilakukan:

\section{Test of Homogeneity of Variances}

Data
\begin{tabular}{|r|r|r|r|}
\hline $\begin{array}{c}\text { Levene } \\
\text { Statistic }\end{array}$ & df1 & df2 & \multicolumn{1}{c|}{ Sig. } \\
\hline 7.886 & 1 & 52 & .007 \\
\hline
\end{tabular}

Tabel hasil uji homogenitas Lavene Test di atas, menunjukan tingkat signifikansi atau nilai probabilitas berada di bawah 0,05 , maka dengan 
demikian data tersebut berasal dari populasi yang mempunyai varians yang berbeda.

3. Uji Korelasi

Correlations

\begin{tabular}{|ll|r|r|}
\hline & \multicolumn{1}{|c|}{$\begin{array}{c}\text { Metode } \\
\text { Magic Story }\end{array}$} & $\begin{array}{c}\text { Mufrodat } \\
\text { siswa }\end{array}$ \\
\hline Metode Magic & Pearson & 1 & $.657^{* *}$ \\
Story & Correlation & & \\
& Sig. (2-tailed) & 27 & .000 \\
& N & $.657^{* *}$ & 27 \\
& Pearson & & 1 \\
Mufrodat siswa & Correlation & .000 & \\
& Sig. (2-tailed) & 27 & 27 \\
& N & \\
\end{tabular}

**. Correlation is significant at the 0.01 level (2-tailed).

Hasil output SPSS di atas nilai pearson correlation antara Metode

Magic Story dengan motivasi belajar sebesar 0,657. Nilai korelasi ini

berada di antara 0,600 sampai dengan 0,799 maka hubungannya adalah

kuat. Artinya hubungan Metode Magic Story dengan peningkatan

mufrodat siswa kuat.

4. R Square (Uji determinasi)

Model Summary

\begin{tabular}{|l|l|r|r|r|}
\hline $\begin{array}{l}\text { Mod } \\
\text { el }\end{array}$ & R & $\begin{array}{c}\text { R } \\
\text { Square }\end{array}$ & $\begin{array}{c}\text { Adjusted R } \\
\text { Square }\end{array}$ & $\begin{array}{l}\text { Std. Error of } \\
\text { the Estimate }\end{array}$ \\
\hline 1 & $.657^{\mathrm{a}}$ & .432 & .409 & 5.49946 \\
\hline
\end{tabular}

a. Predictors: (Constant), Metode Magic Story

Pada tabel di atas terdapat R Square sebesar 0,432 (kuadrat dari

koefisien korelasi 0 ,657). R Square disebut koefisien determinan yang dalam hal ini 43,2\%. Dari nilai tersebut dapat diartikan bahwa 43,2\%

Pengaruh penggunaan metode magic story terhadap peningkatan mufrodat siswa sedangkan sisanya dipengaruhi oleh faktor lain

5. Uji Linieritas

ANOVA $^{\mathrm{a}}$

\begin{tabular}{|l|c|c|c|c|c|}
\hline Model & $\begin{array}{c}\text { Sum of } \\
\text { Squares }\end{array}$ & $\mathrm{df}$ & $\begin{array}{c}\text { Mean } \\
\text { Square }\end{array}$ & $\mathrm{F}$ & Sig. \\
\hline $1{ }_{\mathrm{n}}^{\text {Regressio }}$ & 574.194 & 1 & 574.194 & 18.985 & $.000^{\mathrm{b}}$ \\
\hline
\end{tabular}




\begin{tabular}{|l|r|r|r|l|l|} 
Residual & 756.102 & 25 & 30.244 & & \\
Total & 1330.296 & 26 & & & \\
\hline
\end{tabular}

a. Dependent Variable: Mufrodat siswa

b. Predictors: (Constant), Metode Magic Story

Hasil uji anova tersebut menunjukkan bahwa nilai F hitung sebesar 18,985 dengan taraf signifikansi sebesar 0,000. Nilai ini kemudian dibandingkan dengan $\mathrm{F}$ tabel yang dihitung pada derajat bebas pembilang (df pembilang) sebesar 1 dan derajat bebas penyebut ( $\mathrm{df}$ penyebut) sebesar 25 pada taraf 0,05 yang nilainya adalah 4.24.

Tampak sangat jelas bahwa nilai Fhitung $(18,985)$ lebih besar dari Ftabel (4.24). Sehingga dapat disimpulkan bahwa model yang dihasilkan adalah baik. Hal ini menunjukkan model regresi linear dapat digunakan.

6. Koefisien Regresi

\section{Coefficients $^{a}$}

\begin{tabular}{|l|r|r|r|r|r|}
\hline Model & \multicolumn{2}{|c|}{$\begin{array}{c}\text { Unstandardized } \\
\text { Coefficients }\end{array}$} & $\begin{array}{c}\text { Standardize } \\
\text { d } \\
\text { Coefficients }\end{array}$ & T & Sig. \\
\cline { 2 - 5 } & \multicolumn{1}{|c|}{ B } & Std. Error & \multicolumn{1}{c|}{ Beta } & & \\
\hline $\begin{array}{l}\text { (Constant) } \\
1\end{array}$ Metode Magic \\
Story
\end{tabular}

a. Dependent Variable: Mufrodat siswa

$\mathbf{Y}=\mathbf{a}+\mathbf{b} \mathbf{X}$

$Y$ adalah variabel dependent, dalam hal ini adalah Mufrodat siswa, dan $\mathrm{X}$ adalah variabel independent, dalam hal ini adalah Metode Magic Story. Sedangkan a dan b adalah nilai konstanta yang dicari.

Berdasarkan hasil regrasi diketahui nilai constant-nya adalah 60,162dan nilai Metode Magic Story nilai adalah0,383. Dari keterangan tersebut kita dapat memperoleh persamaan regresi sebagai berikut:

$$
Y=60,162+0,383 X
$$

Nilai konstanta dari koefficien regresi sebesar 60,162, hal ini menyatakan bahwa jika tidak ada kenaikan nilai atau skor 
dari variabel Metode Magic Story nilai, maka variabel Mufrodat siswaadalah 60,162. Koefficien regresi variabel Metode Magic Story nilai sebesar 0,383 menyataakan bahwa setiap terjadi penambahan skor variabel Metode Magic Story akan dapat menambah kenaikan variabel Mufrodat siswa sebesar 0,383.

7. Uji Hipotesis

Setelah megetahui besarnya koefisien regresi, maka perlu dilakukan pengujian hipotesis untuk megetahui apakah terdapat pengaruh atau tidak. Uji hipotesis dapat dinyatakan dengan membandingkan nilai signifikan yaitu

Jika nilai signifikan $>0,05$ dan thitung $<$ tabel, maka $\mathrm{H}_{0}$ diterima

Jika nilai signifikan $<0,05$ dan thitung $>$ tabel, maka $\mathrm{H}_{0}$ ditolak

Jika tabel dicari dengan $\alpha=0,05$ dan (df) n-2 atau $27-2=25$ jadi $t_{\text {tabel }}=1.70814$

Coefficients $^{\mathrm{a}}$

\begin{tabular}{|l|r|r|r|r|r|}
\hline Model & \multicolumn{2}{|c|}{$\begin{array}{c}\text { Unstandardized } \\
\text { Coefficients }\end{array}$} & $\begin{array}{c}\text { Standardize } \\
\mathrm{d} \\
\text { Coefficients }\end{array}$ & \multicolumn{1}{c|}{ S } & \\
\cline { 2 - 5 } & \multicolumn{1}{|c|}{$\mathrm{B}$} & Std. Error & \multicolumn{1}{c|}{ Beta } & & \\
\hline (Constant) & 60.162 & 4.757 & & 12.647 & .000 \\
1 Metode Magic & .383 & .088 & .657 & 4.357 & .000 \\
Story & & & & & \\
\hline
\end{tabular}

a. Dependent Variable: Mufrodat siswa

Berdasarkan hasil uji regresi di atas nilai signifikan sebesar 0,000 dan $\mathrm{t}$ hitung sebesar 4,357. Karena nilai signifikan lebih kecil dari 0,05 dan $t$ hitung $(4,357)$ lebih besar dari t tabel $(1.70814)$ maka Ho ditolak, artinya bahwa ada Pengaruh penggunaan metode magic story terhadap peningkatan mufrodat siswa.

\section{Kesimpulan}

Setelah peneliti membahas tentang penerapan Teknik Magic Story terhadap penguasaan mufrodat siswa di MTs Darul Masholeh yang diperoleh melalui pretest dan posttest, maka dapat disimpulkan sebagai berikut:

Kemampuan siswa terhadap penguasaan mufrodat sebelum menggunakan metode Magic Story tidak ada peningkatan nilai yang tinggi. Nilai siswa pada prestest diperoleh nilai terendah 33, median 53, nilai tertinggi 73 dengan mean atau rata-rata 52,74. 
Kemampuan siswa terhadap penguasaan mufrodat dengan menggunakan metode Magic Story terdapat peningkatan nilai yang tinggi. Nilai siswa pada posttest diperoleh nilai terendah 73 , median 80 , nilai tertinggi 93 dengan mean atau rata-rata 80,37.

Pengaruh penggunaan metode Magic Story terhadap penguasaan mufrodat siswa Berdasarkan hasil uji regresi di atas nilai signifikan sebesar 0,000 dan thitung sebesar 4,357. Karena nilai signifikan lebih kecil dari 0,05 dan t hitung $(4,357)$ lebih besar dari t tabel $(1.70814)$ maka Ho ditolak, artinya bahwa ada Pengaruh penggunaan teknik magic story terhadap penguasaan mufrodat siswa.

\section{Daftar Pustaka}

Al-Khuli, Muhammad 'Ali. 1986. Asaaliib Tadriis al-Lughah al-'Arabiyyah. Riyadh: tidak diterbitkan.

Al-Fauzan, Abdurrahman bin Ibrahim. 1425. Duruus ad-Dauraat at-Tadriis li Mu'allimii al-Lughah al-'arabiyyah lighairi an-Naathiqiina bihaa (al-Jaanib an-Nazharii). Muassasah al-Waqfi al-Islaamii, Masyruu' al-'Arabiyyah lil jamii'.

an-Naqah, Mahmud Kamil. 1985. Ta'liim al-Lughah al-'Arabiyyah bi Lughaah Ukhra: Ususuhu-Madaakhiluhu-Thuruq Tadriisihi. Makkah alMukarramah: Jaami' ah Ummul Qura.

Badawi, Kamal Ibrahim dan Abdullah Hatim. 1995. Thariqah Tadriis alLughah al-'Arabiyyah. Kairo: al-Ma'ariff.

Effendy, Ahmad Fuad. 2005. Metodologi Pengajaran Bahasa Arab. Malang: Misykat.

Mustofa, Syaiful. 2011. Strategi Pembelajaran Bahasa Arab Inovativ. Malang: UIN Press.

Musthofa, Bisri dan Hamid M. Abdul. 2012. Metode E Stategi Pembelajaran Bahasa Arab. Malang: UIN Maulana Malik Ibrahim Press.

Nuha, Ulin. 2012. Metodologi Super Efektif Pembelajaran Bahasa Arab. Jogjakarta: Diva Press.

Sapri, Metode Pembelajaran Bahasa Arab: antara Tradisional dan Modern (Insania Vol 13. Vol. 13, No. 3, 1 Sep-Des 2008: 441-452

Shiinii, Mahmud Ismail, dkk. 1995. Mursyid al-Mu'allim fii Tadriis alLughah al-'Arabiyyah lighairi an-Naathiqiina bihaa. Maktab at-Tarbiyyah al-'Arabiyyah. 
Thuaimah, Rusydi Ahmad. 1986. al-Marja' fii Ta'liim al-Lughah al'Arabiyyah lii an-Naathiqiina bi Lughaatin Ukhra. Makkah: Jaami'ah Ummul Qura.

Thuaimah, Rusydi Ahmad. 1989. Ta'liim al-'Arabiyyah lighairi anNaathiqiina bihaa. ar-Ribaath: Mausyuuraat al-Munazzhamah alIslaamiyyah wa al-'Uluum wa ats-Tsaqaafah.

Wijaya, Erwin Kurnia. 2016. 3 M Magic Memory for Muslim. Surabaya: Genta Group Production. 